\title{
The treatment of jaundice due to liver metastases by quadruple chemotherapy
}

\author{
J. HugheS \\ M.R.C.P., D.M.R.T. \\ T. A. M. STOKer \\ M.D., F.R.C.S.
}

Westminster Hospital, London, S.W.1

\begin{abstract}
Summary
This is a report of seven patients with jaundice due to extensive hepatic secondary deposits, who were treated with combination chemotherapy.

In six cases the jaundice was relieved and biochemical and liver function tests improved.

Three patients survived for 1 year or longer.
\end{abstract}

\section{Introduction}

Although it is recognized that patients with liver metastases from malignant tumours may live for considerable periods of time, it is our experience that the onset of deep jaundice is a very poor prognostic sign. This is often regarded as a hopeless clinical situation and an indication for symptomatic treatment only. The development of combination regimens of chemotherapy has allowed more effective treatment of some solid tumours without unacceptable toxic side-effects. At this hospital considerable experience has now been gained in the treatment of solid tumours using one such regimen (Hanham, Newton \& Westbury, 1971).

This report concerns seven consecutive patients who presented with jaundice due to metastases from various malignant tumours, and who were treated with quadruple chemotherapy. The technique that has been used in each of these patients is a modification of that of Costanzi \& Coltman (1969) and is shown in Table 1. Courses of treatment are usually

TABLE 1. Quadruple chemotherapy

\begin{tabular}{ll}
\hline Drug & Schedule \\
\hline Cyclophosphamide & $200-300 \mathrm{mg}-2$ doses, days 1 and 5 \\
Methotrexate & $0.25 \mathrm{mg} / \mathrm{kg} /$ day -2 doses, days 1 and 4 \\
Vincristine & $0.015 \mathrm{mg} / \mathrm{kg} /$ day -2 doses, days 2 and 5 \\
5-fluorouracil & $7.5 \mathrm{mg} / \mathrm{kg} /$ day-daily for 5 days \\
\hline
\end{tabular}

given in hospital at intervals of 3 weeks, although if the clinical condition deteriorates the interval between courses may be shortened. In one patient, whose condition had been satisfactorily stabilized, it was possible to lengthen the interval to 8 weeks between courses and to continue treatment on an out- patient basis. Alopecia developed in all seven patients, but in those who survived for longer than $\mathbf{3}$ months there was regrowth of hair. Nausea occurred in all cases, but was easily controlled by anti-emetics. There were no other serious side-effects, and in no case was the treatment interrupted due to intolerance of the drugs.

\section{Case 1}

Mrs M. L. Born 1920. Housewife. This patient underwent a right radical mastectomy for carcinoma in 1962 and developed a metastatic ovarian tumour in January 1971. Bilateral oophorectomy was performed, but later she developed a palpable epigastric mass and underwent a partial hepatic lobectomy for a solitary metastasis. A bilateral adrenalectomy was performed at the same time. In September 1971, she returned with deep jaundice and gross hepatomegaly. Three courses of chemotherapy were given at 4 week intervals. The plasma bilirubin level fell from 11 to $1 \cdot 1 \mathrm{mg} / 100 \mathrm{ml}$ (Table 2). However, her general condition deteriorated and she died $2 \frac{1}{2}$ months after the onset of jaundice.

\section{Case 2}

Mrs G. W. Born 1906. University lecturer. She presented in April 1971 with jaundice (bilirubin level $18 \mathrm{mg} / 100 \mathrm{ml}$ ), weight loss and malaise. Her right breast had been ulcerated for a year and there was a fixed axillary lymph node present as well as a small pleural effusion and massive hepatomegaly. Biopsy of the breast confirmed carcinoma. Treatment with oestrogens had no effect. Combination chemotherapy was started and after four courses the jaundice subsided and her clinical condition improved so that she was able to return to work (Table 2). After eight courses of treatment the interval between courses increased to 8 weeks. This was undertaken as an out-patient and she is now quite well 18 months after her presentation.

\section{Case 3}

Mr R. W. Born 1953. Student. He presented in 1968 with an alveolar rhabdomyosarcoma of the left 
TABLE 2. Serum bilirubin levels $(\mathrm{mg} / 100 \mathrm{ml})$ after chemotherapy

\begin{tabular}{|c|c|c|c|c|c|c|c|}
\hline $\begin{array}{l}\text { Days after } \\
\text { start of } \\
\text { chemotherapy }\end{array}$ & Case 1 & Case 2 & Case 3 & Case 4 & Case 5 & Case 6 & Case 7 \\
\hline 0 & $11 \cdot 0$ & $18 \cdot 2$ & $10 \cdot 7$ & $6 \cdot 8$ & 18.0 & $24 \cdot 0$ & $3 \cdot 8$ \\
\hline 10 & $10 \cdot 2$ & $17 \cdot 5$ & 10.0 & $14 \cdot 5$ & $13 \cdot 5$ & $12 \cdot 0$ & $4 \cdot 6$ \\
\hline 20 & $9 \cdot 4$ & $12 \cdot 0$ & $3 \cdot 7$ & $21 \cdot 0$ & $7 \cdot 5$ & $7 \cdot 5$ & $5 \cdot 5$ \\
\hline 30 & $8 \cdot 5$ & $5 \cdot 4$ & $2 \cdot 0$ & $22 \cdot 8$ & $4 \cdot 5$ & $3 \cdot 6$ & $6 \cdot 4$ \\
\hline 40 & $6 \cdot 0$ & $3 \cdot 1$ & $1 \cdot 6$ & $11 \cdot 0$ & $1 \cdot 3$ & $3 \cdot 3$ & $7 \cdot 2$ \\
\hline 50 & $3 \cdot 7$ & $1 \cdot 0$ & $1 \cdot 2$ & $4 \cdot 7$ & 0.9 & $2 \cdot 8$ & $8 \cdot 1$ \\
\hline 60 & $1 \cdot 0$ & 0.8 & 0.9 & $1 \cdot 5$ & 0.5 & $2 \cdot 4$ & $8 \cdot 9$ \\
\hline 70 & $1 \cdot 0$ & 0.7 & 0.7 & $1 \cdot 8$ & 0.5 & $1 \cdot 8$ & $9 \cdot 2$ \\
\hline 80 & 1.0 & 0.7 & 0.6 & $3 \cdot 2$ & $1 \cdot 0$ & $1 \cdot 5$ & $9 \cdot 5$ \\
\hline
\end{tabular}

foot which was locally excised. In April 1969 extensive cutaneous and intrathoracic deposits appeared with jaundice (bilirubin $11 \mathrm{mg} / 100 \mathrm{ml}$ ) and massive hepatomegaly. Quadruple cytotoxic therapy was started and the jaundice cleared (Table 2). He remained well until May 1970 when secondary deposits were confirmed in the liver at laparotomy. In all, he had seventeen courses of quadruple chemotherapy before his death in December 1970. He survived 20 months on this treatment.

\section{Case 4}

Mrs C. B. Born 1918. Housewife. This patient was treated in 1968, for an extensive Stage IV carcinoma of the right breast, by radiotherapy and oophorectomy. The following year hepatic metastases became apparent and bilateral adrenalectomy was performed. In May 1971 she became deeply jaundiced with a bilirubin of $24 \mathrm{mg} / 100 \mathrm{ml}$. A liver scan confirmed multiple metastases. Combination chemotherapy was initiated and the jaundice decreased (Table 2). Three course of treatment were given but she died 4 months after developing jaundice.

\section{Case 5}

Mrs J. C. Born 1919. Housewife. She first presented in July 1970 with disseminated carcinoma of the breast which was treated initially with parenteral Durabolin with no response. In October 1970 jaundice developed (bilirubin $17 \mathrm{mg} / 100 \mathrm{ml}$ ) with massive hepatomegaly. Quadruple chemotherapy was given and resulted in remission of jaundice. Her clinical condition improved and this was confirmed by improvement of liver function tests (Table 2) and serial liver scans. She survived for 12 months on chemotherapy.

\section{Case 6}

Mr R. K. Born 1925. Schoolteacher. He underwent a sub-total gastrectomy in 1969 for a prepyloric tumour which histologically was a poorly differentiated adenocarcinoma. He was referred to this hospital in March 1971, deeply jaundiced with a plasma bilirubin of $19 \mathrm{mg} / 100 \mathrm{ml}$ and gross hepato- megaly. Metastases were confirmed by the liver scan appearance. Three course of quadruple chemotherapy were given with improvement in liver function tests (Table 2). Isotope scans showed decrease in liver size and in size of filling defects. He survived for 3 months. At the time of his death his bilirubin was $1.5 \mathrm{mg} / 100 \mathrm{ml}$.

\section{Case 7}

Mr H. D. Born 1908. Clerk. He presented in February 1970 with multiple subcutaneous nodules and jaundice. Chest X-ray indicated a carcinoma of the bronchus and a biopsy of a cutaneous nodule showed oat cell carcinoma. He was treated with monthly quadruple chemotherapy. His general codition improved initially, although his jaundice gradually deepened and was increasing rapidly until the time of his death (Table 2) in August 1970. Necropsy confirmed multiple metastases from carcinoma of bronchus.

\section{Discussion}

It has been shown in the case of breast tumours that patients with extensive liver metastases or jaundice respond very poorly to bilateral adrenalectomy (Schmidt et al., 1971). Jaffe et al. (1968) showed that the median survival after diagnosis of liver secondaries in various carcinomas was $\mathbf{7 5}$ days, and the presence of jaundice reduced the median survival to 33 days. The influence of various forms of treatment on liver metastases was studied by Mansfield, Kramer \& Southard (1970) who investigated the effect of radiotherapy and of single cytotoxic agents on liver metastases by studying the survival of the patients once hepatic metastases had been diagnosed, and by investigating the effect of the agents on the uptake of radioactive isotopes by the liver. They concluded that neither radiotherapy nor chemotherapy affected the length of survival of the patients. Rapoport \& Burleson (1970) showed that 5-fluorouracil given intravenously had no effect on survival time, and that those patients with massive hepatomegaly and jaundice had the poorest prognosis. 
TABLE 3. Serum level of alkaline phosphatase (KA units) after chemotherapy

\begin{tabular}{crrrrrrr}
\hline $\begin{array}{c}\text { Days after } \\
\text { start of } \\
\text { chemotherapy }\end{array}$ & Case 1 & Case 2 & Case 3 & Case 4 & Case 5 & Case 6 & Case 7 \\
\hline 0 & 150 & 84 & 162 & 27 & 114 & 240 & 50 \\
10 & 130 & 109 & 168 & 53 & 62 & 190 & 43 \\
20 & 108 & 70 & 105 & 52 & 90 & 87 & 37 \\
30 & 85 & 35 & 53 & 56 & 52 & 40 & 30 \\
40 & 74 & 28 & 41 & 50 & 35 & 43 & 24 \\
50 & 62 & 25 & 29 & 45 & 28 & 52 & 17 \\
60 & 50 & 25 & 27 & 40 & 25 & 60 & 10 \\
70 & 47 & 24 & 25 & 34 & 21 & 70 & 15 \\
80 & 44 & 25 & 23 & 32 & 20 & 80 & 19 \\
\hline
\end{tabular}

However, Sullivan (1965) and Ansfield et al. (1971) reported a palliative effect, using intra-arterial infusion of 5-fluorouracil into the hepatic artery, in a variety of metastatic liver tumours. $61 \%$ of their cases showed clinical improvement: many of these cases were jaundiced. The jaundice resolved and there was an improvement in disordered liver func. tion. This method has the disadvantage of long-term intra-arterial cannulation.

The results of treatment of these seven unselected jaundiced patients are encouraging. There were four breast carcinomas, one gastric carcinoma, one alveolar rhabdomyosarcoma and an oat-cell carcinoma of the bronchus. With the exception of the oat-cell carcinoma, the jaudice was relieved. Three cases survived for a year or more: of these three cases, two patients returned to a normal life in the face of what is generally regarded as an extremely unfavourable clinical situation. The longest survivor under treatment was the patient with the alveolar rhabdomyosarcoma who lived 20 months. One patient with a breast tumour is quite well 18 months after quadruple therapy was initiated.

In the six cases which responded to chemotherapy, the level of the plasma alkaline phosphatase, aspartate aminotransferase (SGOT) and alinine aminotransferase (SGPT) fell in parallel with the fall in total bilirubin (Table 3). In three cases the uptake of radioactive isotope by the liver returned to a more normal picture.

\section{Acknowledgments}

We wish to thank Dr K. A. Newton, Professor H. Ellis, Dr I. W. F. Hanham and Mr C. Wastell for permission to report patients admitted under their care and for their help in the preparation of this paper.

\section{References}

Ansfield, F.J., Guillermo, R., SkibKa, R., Bryan, G.T., DAVIS, A.L. \& WIRTANEN, G.W. (1971) Intrahepatic arterial infusion with 5-fluorouracil. Cancer, 28, 1147.

Costanzi, J.J. \& Coltman, F.J. (1969) Combination chemotherapy using cyclophosphamide, vincristine, methotrexate and 5-fluorouracil in solid tumours. Cancer, 23, 589.

Hanham, I.W.F., Newton, K.A. \& Westbury, G. (1971) Seventy-five cases of solid tumours treated by a modified quadruple chemotherapy regimen. British Journal of Cancer, 25, 462 .

JafFe, B.M., Donegan, W.L., Watson, F. \& Spratt, J.S. (1968) Factors influencing survival in patients with untreated hepatic metastases. Surgery Gynecology and $O b$ stetrics, $127,1$.

Mansfield, C.M., Kramer, S. \& Southard, M.E. (1970) The influence of treatment on the survival of patients with hepatic metastases diagnosed by liver scanning. American Journal of Roentgenology, 109, 749.

RAPOPORT, A.H. \& BURLESON, R.L. (1970) Survival of patients treated with systemic fluorouracil for hepatic metastases. Surgery Gynecology and Obstetrics, 130, 773.

SChmidt, M.L., Nemoto, T., DaO, T. \& Bross, I.D.J. (1971) Prognostic factors affecting adrenalectomy in patients with metastatic cancer of the breast. Cancer, 27, 1106.

Sullivan, R.D. (1965) Chemotherapy for liver cancer by protracted ambulatory infusion. Journal of the American Medical Association, 194, 481. 